\title{
CORRELATIVE MODELING TECHNIQUES TO REDUCING UNCERTAINTIES IN A COMPLEX MARGINAL FIELD IN THE NIGER DELTA.
}

\author{
A. J. ILOZOBHIE AND D. I. EGU \\ (Received 2 July 2018; Revision Accepted 20 August 2018)
}

\begin{abstract}
Deterministic and probabilistic re-evaluation was used in handling predetermined six uncertainties in five wells in Isand reservoir. Results of low case (LC) modeled string showed that the I-sand reservoir is severely deformed by faults and this was confirmed with a predicted high case $(\mathrm{HC})$ modeled string. When structure was sensitized at a bulk volume of 10,964 STB with porosity of 0.266 , water saturation of 0.43 and net to gross ratio (NTG) of 0.75 and initial oil formation volume factor (Boi) of 2.2bbl/stb, the resultant estimated stock tank initial oil in place (STOIIP) gave $5,892,752.65$ STB or the base case. The corresponding STOIIP for the low and high case are $5,198,470.887$ STB and $6,451,196.678 S T B$. Results of deterministic analysis shows that the low case results gave a minimum value of 5.20MMSTB for structures and maximum value of 6.2MMSTB for water saturation. High case results revealed a maximum of 6.45MMSTB for structures and a minimum value of 5.69MMSTB for water saturation. Results of high, low and base cases were used to quantify some of the uncertainties in the volumetric estimation and subsequently in the probabilistic method.

This work clearly shows the viability of the pragmatic approach used to quantify the uncertainty ranges in reservoir parameters and their impact on the statics volumes as well as recovery.
\end{abstract}

KEYWORDS: deterministic, probabilistic, modeled, structures, water saturation, net to gross ratio

\section{INTRODUCTION}

The technical constraints usually imposed by the management of most marginal of most marginal oil/gas Field is largely hinged on challenges of uncertainties during exploration and exploitation procedures. Some of these critical factors includes complex reservoir structures (Haldorsen and Damsleth, 1993), size of reserves, non-availability of large data volume, environmental concerns, political instability, high cost of re-development, complicated legal issues and more importantly economic constraints compounded by low prices of crude oil and natural gas assets (Ayoola, 2004; DPR 1996). Improvement in the viability of a marginal Field is however dependent on improvement in technical and economic conditions which may kick start the development of a marginal Field (Efeotor, 1999; Floris and Peersmann, 2002; Grat, 2005).

Most marginal fields require integrated synergized special field development planning and accurate reservoir management strategies in order to yield acceptable returns on investment. This attention is largely due to the uncertainty that prevails in all facets of the oil and gas industry as was studied in this work which is an onshore marginal field (Fig.1) and some of those identified are; facies modelling, data processing and interpretation, subsurface geological structural modelling, seismic, well $\log$ and aeromagnetic data interpretation challenges (llozobhie, et al., 2014), detailed petrophysical estimations (llozobhie, et al 2015), reservoir fluid transmissibility correlations, and dynamic and static flow simulation modelling, which affects the way we understand the reservoir pattern, making reliable production forecasts and risk-free decisions.

\section{Deterministic evaluation}

A deterministic mathematical model is meant to yield a single solution describing the outcome of some "experiment" or procedures used given appropriate inputs (Castillo et al., 1998; Cooper, 2005). The procedure is to select a single value for each parameter to input into an appropriate equation, to obtain a single answer.

Deterministic models are applicable only when the processes that generated the data are known in enough detail that an accurate description of the entire population can be made from only a few sample values. Unfortunately, though, very few earth science processes are understood so well. Although we know the physics or chemistry of the fundamental processes (e.g.,

\section{A.J. Ilozobhie, Department of Physics, University of Calabar, Calabar, Nigeria.}

D. I. Egu, Department of Physics, University of Calabar, Calabar, Nigeria. 
depositional mechanisms, tectonic processes, and diagenetic alterations), the variables we study in earth science data sets are the products of a vast number of complex interactions that are not fully quantifiable (Egbogah, 2008).

\section{Probabilistic evaluation}

The random function model concept introduced in this section recognizes this fundamental uncertainty and provides the tools not only to estimate values at unsampled locations, but also to measure the reliability of such estimates (Bickel and Bratvold 2008). The probabilistic method, on the other hand, is more rigorous and less commonly used. This method utilizes a distribution curve for each parameter. Assuming good data, a lot of qualifying information can be derived from the resulting statistical calculations, such as the minimum and maximum values, the mean (average value), the median (middle value), the mode (most likely value), the standard deviation and the percentiles. The probabilistic methods have several inherent problems. They are affected by all input parameters, including the most likely and maximum values for the parameters. In such methods, one cannot back calculate the input parameters associated with reserves. Only the end result is known but not the exact value of any input parameter. On the other hand, deterministic methods calculate reserve values that are more tangible and explainable. In these methods, all input parameters are exactly known; however, they may sometimes ignore the variability. Probabilistic model is, instead, meant to give a distribution of possible outcomes (i.e. it describes all outcomes and gives some measure of how likely each is to occur).

The two models can be used to evaluate some of the uncertainties in the volumetric parameters. Erratic sand development paucity of biostratigrahic control coupled with a complex structure make the 1-sand complex of the field of study one of the least understood hydrocarbon reservoirs of the Northern depobelt onshore of the Niger Delta, Nigeria (Ilozobhie and Egu, 2013). The field of study is located some $80,000 \mathrm{~m}$ North-West of Yenegoa in the Niger Delta (Fig. 1).

The field was discovered by exploration well 1 in 1978 and covers an area of approximately 20,000 sq. m, oriented East-West. It came on stream in 1983, but was later abandoned.

The field is a sample fault-bound rollover structure with dip closure located to the south of the growth fault that defines the northern limit of the field. Hydrocarbon occurrences in the field of study are located within a coastal plain/fluvio-deltaic sequence.

\section{MATERIALS AND METHODS}

Materials used for this study are suites of seismic sections, well logs, base map (Fig. 2), time to depth conversion chart, reservoir data and petrel software. Reasons for the choice of this technique are to carefully appraise static and dynamic modeling synergizing deterministic and probabilistic methods to improve interpretation of the uncertainties (Gilman et al., 1998). Uncertainty handling methodology used for the purpose of defining static hydrocarbon volumes are;

Deterministic evaluation: The deterministic approach was based on the use of static and dynamic model realizations to quantify the uncertainty.

This approach is to evaluate uncertainty of the volume of fluids in place (STOOIP) in the 1 Sands. Other parameters used for this estimation are the reservoir thicknesses, initial water saturation, net-to-gross ratio, reservoir area, porosity and the initial oil formation volume factor.

. The STOOIP for each zone was determined from the equation below;

STOOIP $=\frac{7758 \times \mathrm{Ar} \times \mathrm{ht} \times\left(\frac{\mathrm{N}}{\mathrm{G}}\right) \times \emptyset \times(1-\mathrm{Swi})}{\mathrm{B}_{\mathrm{oi}}}$

Where;

$\mathrm{B}_{\mathrm{oi}}=$ Oil formation Volume Factor

$A_{r}=$ Area of reservoir.

$\mathrm{N}=$ Net formation thickness

$\mathrm{G}=$ Gross formation thickness

$h_{t}=$ Total formation thickness of the oil zone.

$\Phi=$ Porosity of the oil zones.

$\mathrm{S}_{\mathrm{wi}}=$ Initial water saturation.

The area, gross thickness and oil formation volume factor were kept constant in this work. Using the equation above, the STOOIP were generated for each zone. The uncertainty in STOOIP was then evaluated to calculate the P10, P50 and P90 values.

A method and procedure for modeling the 1 Sands has been presented. The method accounts for the uncertainty in the calculation for STOOIP in an oil.

Probabilistic evaluation: The common method for calculating statistical uncertainty is to generate Probability Distribution Functions (PDFs) for each volumetric parameter such as Gross Rock Volume, porosity, Net-To-Gross, hydrocarbon saturation and formation volume factor (llozobhie, et al., 2015). This study was conducted in the North-West of Yenegoa in the Niger Delta (Fig. 1).

Main uncertainties affecting STOIIP: The main uncertainties affecting the evaluation of stock tank oil initially in place (OIIP) for the reservoir as seen in this study are;

- Gross rock volume

- Porosity

- Hydrocarbon saturation-HC (capillary pressure curves)

- Net-to-gross ratio Formation volume factor

Gross Rock Volume (GRV): Structural and sedimentological settings and evaluation has been exhaustively discussed. The main uncertainties associated with the structure included horizon picking and correlation, fault plane definition and time to depth conversion (velocity variations).

Horizon picking: Data quality may have been impacted by the geology of the area, which showed high level of 
slumping, sediment deformation and channeling which resulted in very poor, unstable, discontinuous and complex loops at the G-Sands level. This situation was further compounded by the paucity of check shot data, which constrained well-to-seismic tie.

The choice of the combined velocity model based on time depth (TZ) and Migration velocity as the most-likely model was based on the fact that it provided the platform for the integration of all available data.

Fluid contacts: Only well Dan-004 logged an Oil-WaterContact (OWC) of 9,700ft at the flank. The uncertainty in the contact has been determined at +10 and $15 \mathrm{ft}$ to account for the possible variation across the shaly intervals and the effect of this on the OWC. The most crestal well (well Dan-002) did not encounter any gas.
No Gas-Oil-Contact (GOC) was assumed present in the reservoir.

\section{COMPARISON}

Uncertainty in the input data compared to the probabilistic methods allows the incorporation of more variance in the data. A comparison of the deterministic and probabilistic methods, however, can provide quality assurance for estimating hydrocarbon reserves; i.e. reserves are calculated both deterministically and probabilistically and the two values are compared. If the two values agree, then confidence on the calculated reserves is increased. If the two values are away different, the assumptions need to be reexamined. 


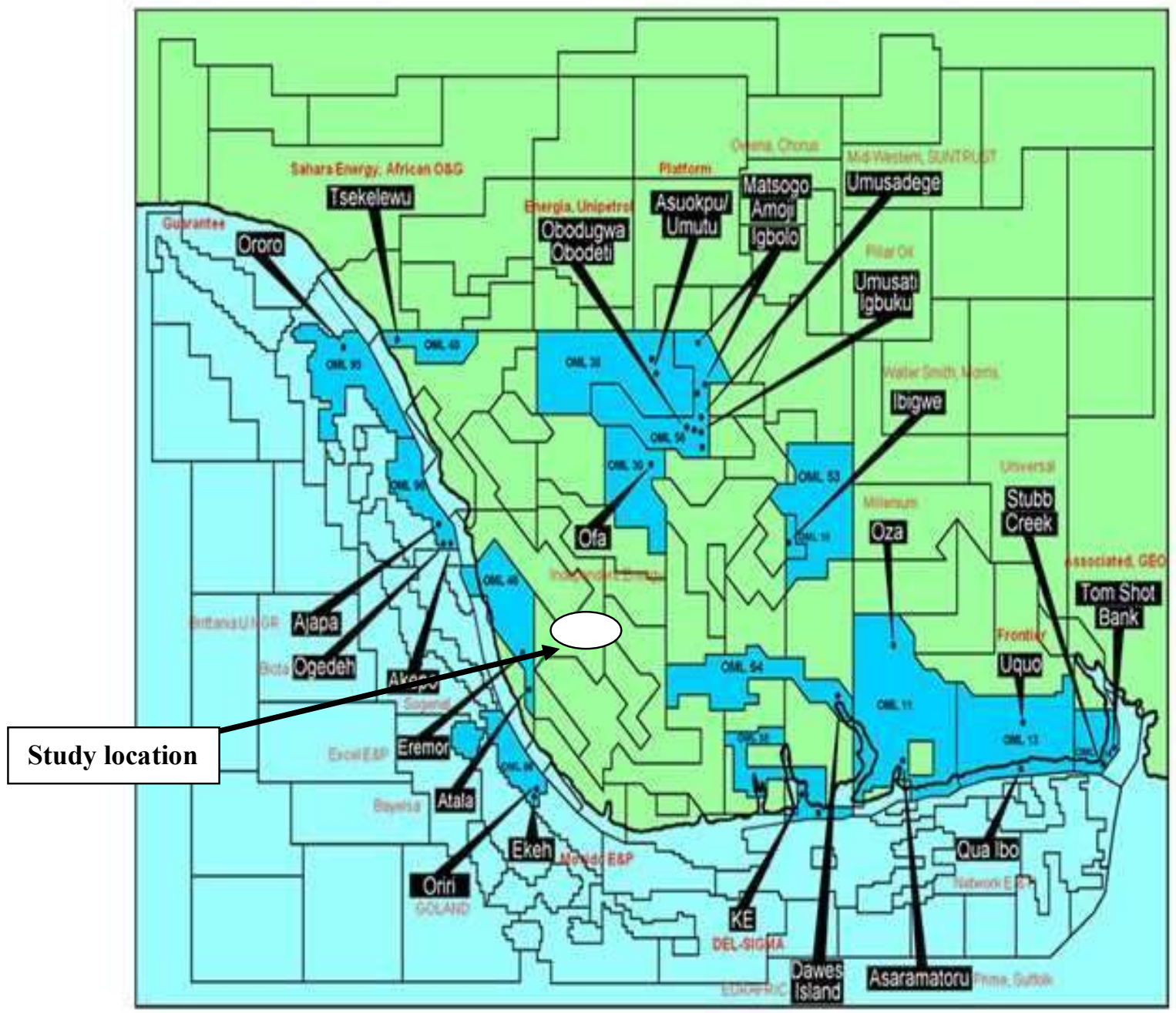

Fig. 1: Niger-Delta Marginal Fields Concession \& Their Operators (DPR, 1996)

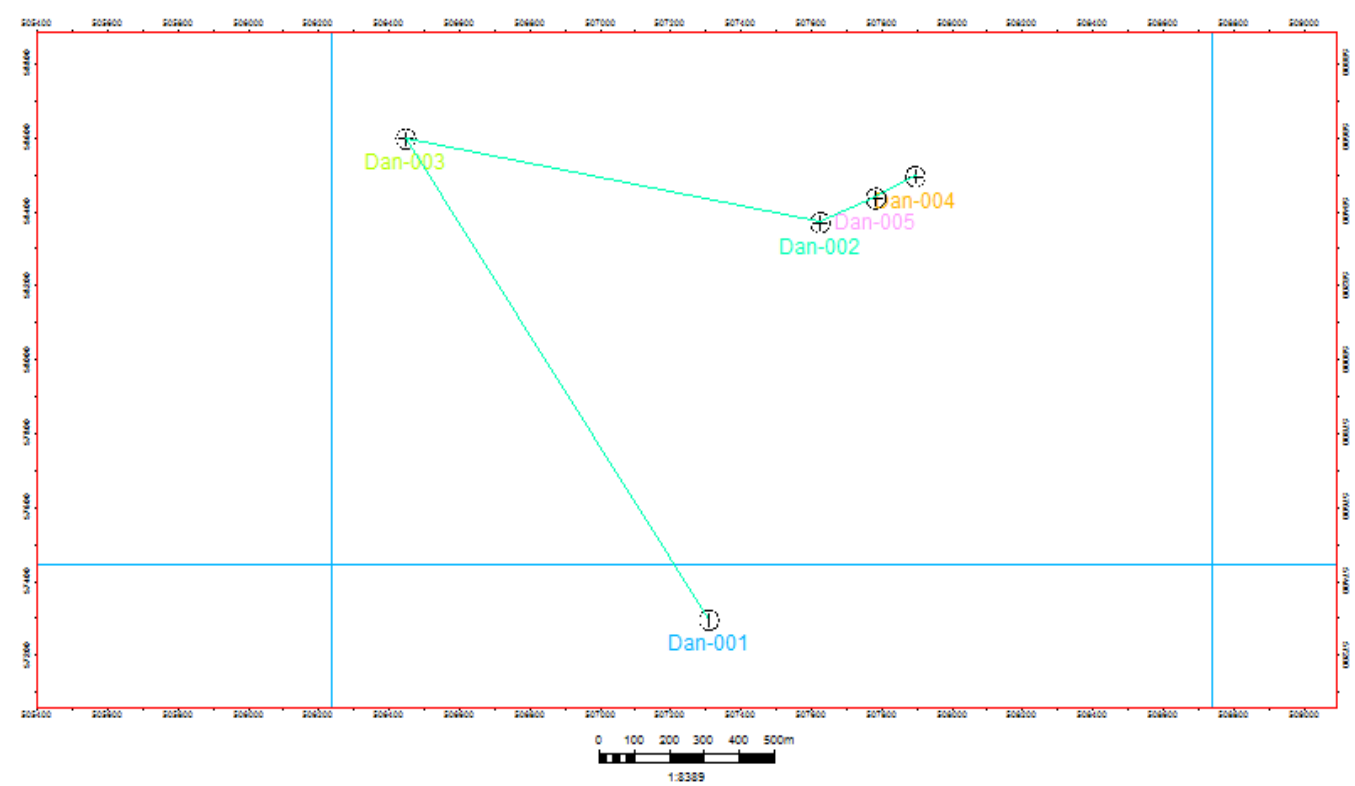


Porosity: Porosities were evaluated from porosity logs at the well positions across the vertical interval of the reservoir.

Net to gross ratio: Technique used for the porosity estimation spread was also adopted for the N/G parameter. The density neutron log separation DNS adequately identifies the shale from sands over most of the intervals more especially in radioactive sand, where shale was separated based on the fact that neutron lies to the left of the density in shale. The DNS curve was also used as input for estimating the shale volume in the reservoir. Based on the sensitivity that was carried out on the cut-off for the $V_{\text {sh }}$, net/gross was computed and plotted against varying $\mathrm{V}_{\mathrm{sh}}$, net/gross was computed and plotted against varying $V_{\text {sh }}$ cut-off values.

Hydrocarbon saturation (Capillary pressure curves): Hydrocarbon saturations were modeled using capillary pressure curves produced from a log derived

\section{Results of probabilistic approach}

Results showed that the correlated (Fig. 3) horizons for well Dan-002 were the highest hit with an estimated residual standard deviation after simulation of 69.15 while that of well Dan-004 gave 60 . Residual estimations for Dan-001, Dan-005 and Dan-003 are -65.3, 56.4 and 58 (Table 1). The calculated standard deviation was estimated at 35.65 as shown in Table 2.

Horizons was also picked based on the well logs on the correlation panel of the five wells ranging with depths from 9250 - 9920ft in Dan-004, 9290 - 9780ft in Dan 005,9330 - 9820ft in Dan - 002, 9420 - 9760ft in Dan 003 and 10,550 - 11,300ft in Dan - 001 (Fig. 3).

This was used to produce the base case net to gross ratio (NTG). The model results obtained shows high values of NTG (brown color) in the central region of the NTG modeled map and elongating southwards with few patches in the Northern end and flanges of the Northeast and Northwest (Fig. 4).

Results of isopach map probabilistic interpretation for the base case indicated that the deepest horizon (purple) is located southwards with much uncertainties due to the area covered at a maximum depth of $14,500 \mathrm{ft}$ while the shallowest portion is located northwards saturation height function calibrated against nearby field cores analysis (including capillary pressure measurements) was carried out on the acquired core. Height Above Free Water Level (HAFWL) was established from the log of well Dan-004.

Established correlations: A number of correlations were considered namely the Nigerian, Standing, Lasater and Vasques-Beggs correlations. One of these correlations was eventually used after determining its suitability for the I-sand reservoir. PVT samples and reports from reservoirs in the field and nearby fields were validated and characterized and correlations were tested against results of the characterized fluids and the Standing correlation was found to be the most consistent with the experimental data.

\section{RESULTS AND DISCUSSION}

(greenish) with minimum depth of $7,500 \mathrm{ft}$ located in the Northeast flange.

Results of structural map for surface l-sand base case showed presence of fault deformities in the Northern region and running east to west. The central region is characterized by a major fault between 10,000 $12,000 \mathrm{ft}$. This means that the presence of structural deformities is an indicator of the level of uncertainty in the I-sand reservoir (Fig. 6)

Results of low case (LC) modeled string showed that the I-sand reservoir is severely deformed by geologic structures or faults as the case may be and this was confirmed with a predicted high case (HC) modeled string as shown in Table 3. Further simulation of these results showed that when structure was sensitized at a bulk volume of 10,964 STB with porosity of 0.266 , water saturation of 0.43 , net to gross ratio (NTG) of 0.75 and initial oil formation volume factor $\left(B_{o i}\right)$ of 2.2. The resultant estimated stock tank initial oil in place (STOIIP) gave 5,892,752.65STB (Table 4).

This value of STOIIP is the base case. The corresponding STOIIP for the low and high case are $5,198,470.887$ STB and $6,451,196.678$ STB (Table 5). 


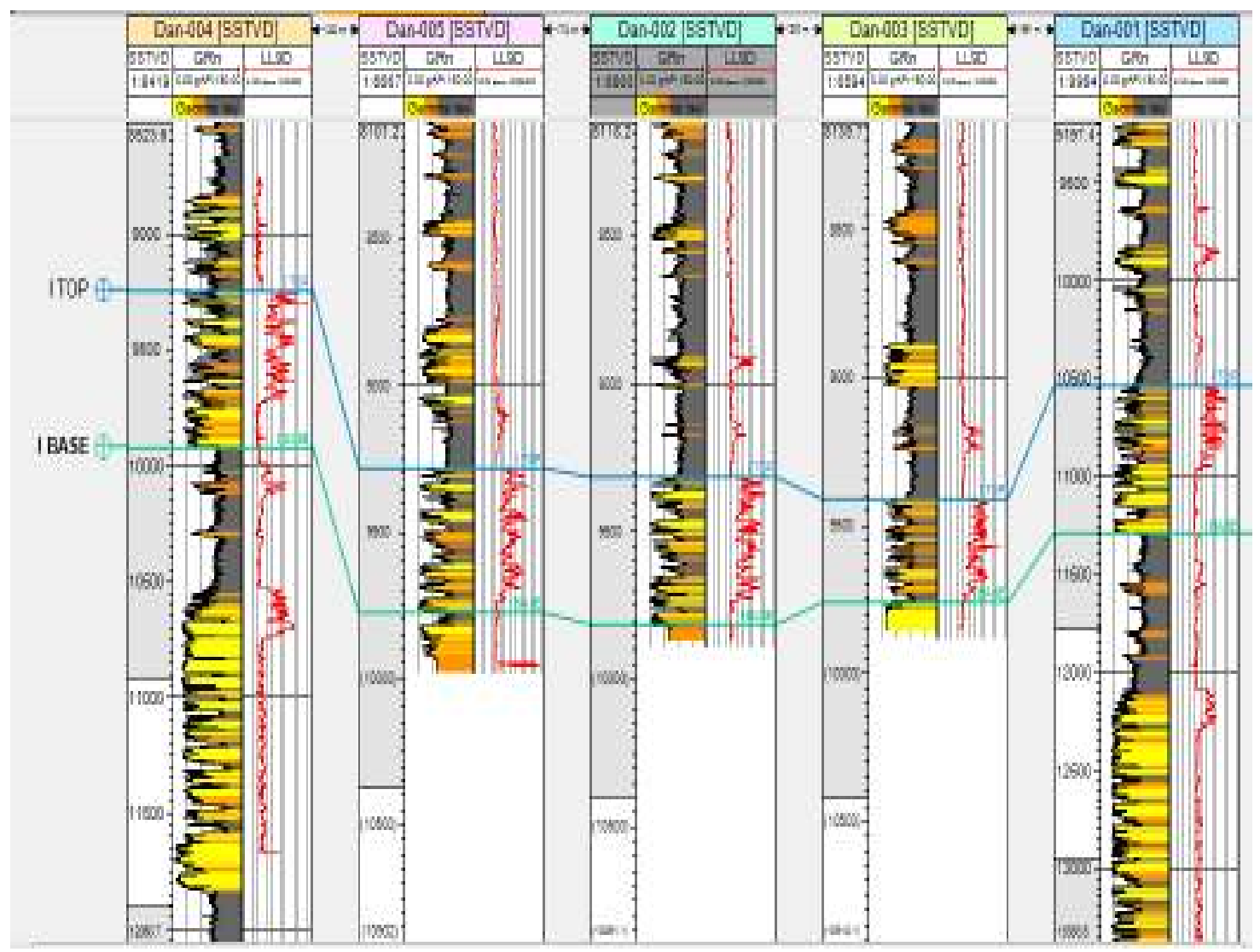

Fig. 3: Sand correlation interpreted from the base map.

TABLE 1: Residual sand correlation uncertainty result for five wells for surface 1

\begin{tabular}{|l|l|l|l|l|l|l|}
\hline well & X-value & Y-value & Z-value & $\begin{array}{l}\text { Horizon } \\
\text { after }\end{array}$ & Residual & Corrected \\
\hline Dan-002 & 507625 & 58375 & -9313.65 & -9382.8 & 69.15 & No \\
\hline Dan-001 & 507309 & 57299 & -10535.14 & -10469.84 & -65.3 & No \\
\hline Dan-005 & 507783 & 58440 & -9280.91 & -9337.31 & 56.4 & No \\
\hline Dan-003 & 506448 & 58601 & -9409.65 & -9467.65 & 58 & No \\
\hline Dan-004 & 507896 & 58499 & -9241.74 & -9301.74 & 60 & No \\
\hline
\end{tabular}

TABLE 2: Results of standard deviation of horizon residuals (disparities).

\begin{tabular}{|l|l|}
\hline & Residual \\
\hline & 69.15 \\
\hline & -65.3 \\
\hline & 56.4 \\
\hline & 58 \\
\hline & 60 \\
\hline Average & $\mathbf{3 5 . 6 5}$ \\
\hline Standard Deviation & $\mathbf{5 6 . 6 5}$ \\
\hline
\end{tabular}




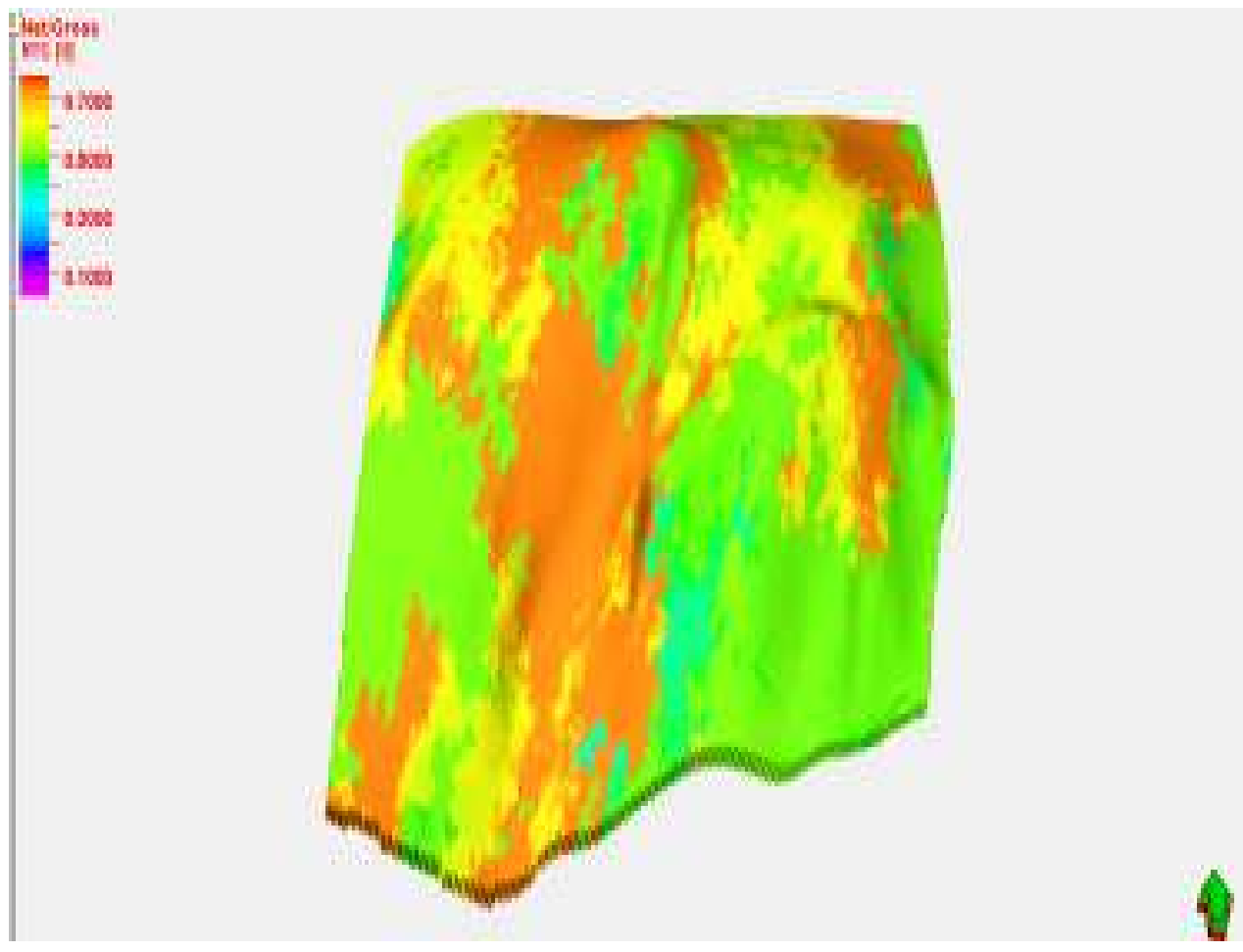

Fig. 4: Result of the base case net to gross (NTG) ratio model

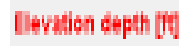

$$
\begin{aligned}
& -30000 \\
& -460060 \\
& \text { - } \\
& \text { - } \\
& \text { - } 110000 \\
& \text { - } 1300060 \\
& \text { - } 154000
\end{aligned}
$$

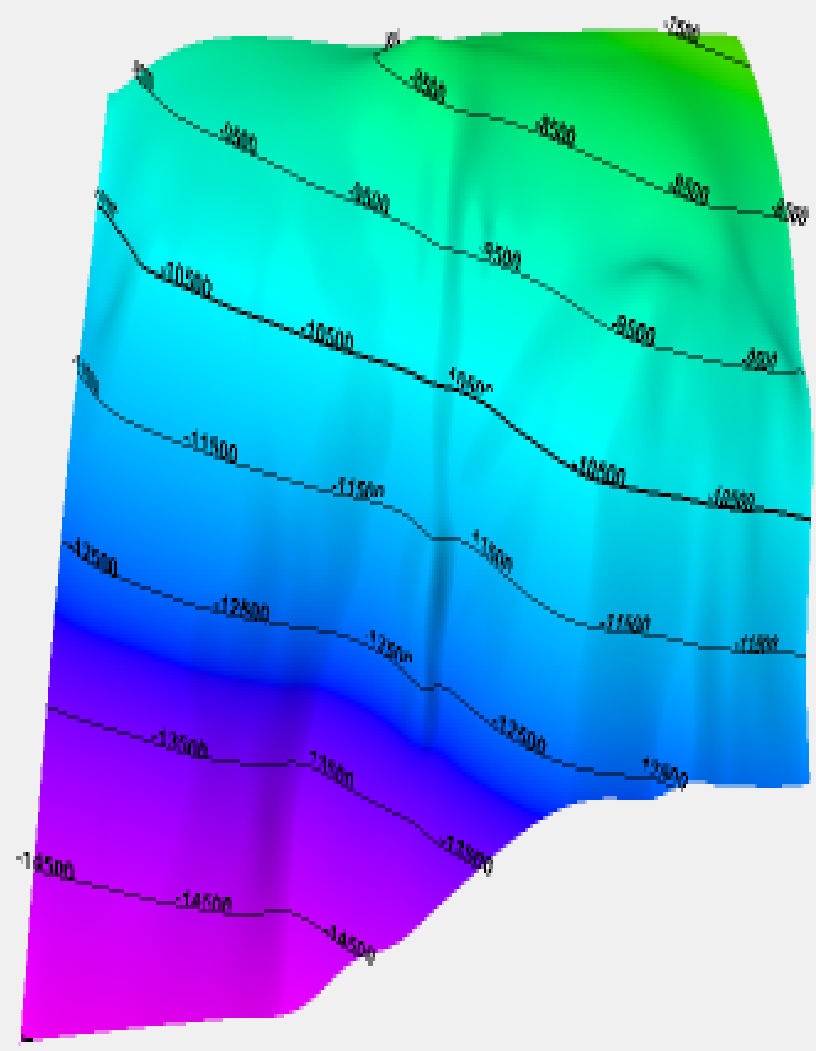


Fig. 5: Result of isopach map probabilistic interpretation for the base case

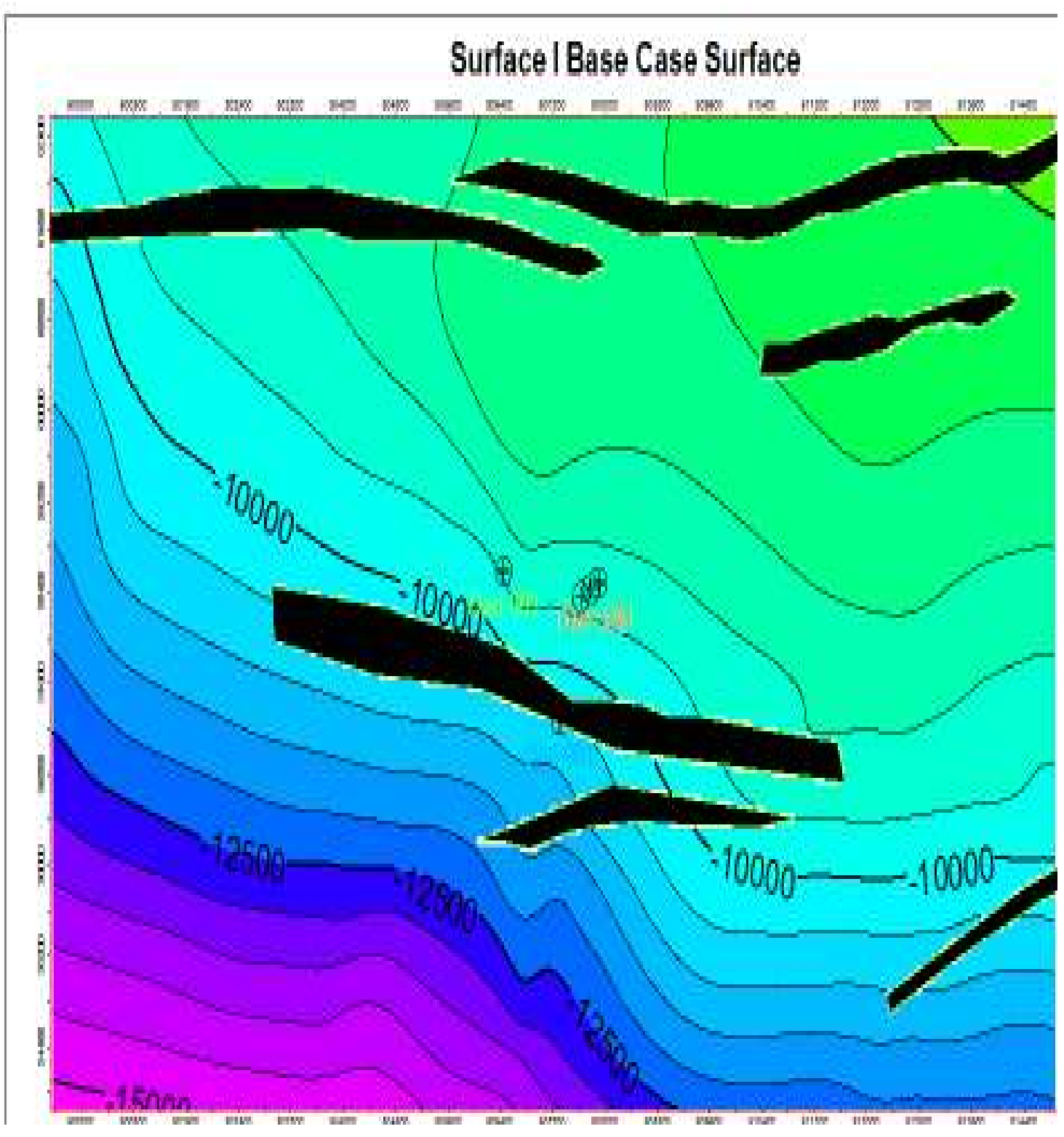

Fig. 6: Check-short data showing a Base Case Structural Map. 
TABLE 3: Results of low and high case strings

\begin{tabular}{|c|c|c|c|c|c|c|}
\hline \multicolumn{7}{|c|}{ Low case (LC) Model string } \\
\hline Reservoir & structure & contact & Sw & NTG & porosity & Bo \\
\hline I & LC & $B C$ & $\mathrm{BC}$ & $\mathrm{BC}$ & BC & $\mathrm{BC}$ \\
\hline \multicolumn{7}{|c|}{ High case (HC) Model string } \\
\hline Reservoir & structure & contact & Sw & NTG & porosity & Bo \\
\hline I & $\mathrm{HC}$ & $\mathrm{BC}$ & $\mathrm{BC}$ & $\mathrm{BC}$ & $\mathrm{BC}$ & $\mathrm{BC}$ \\
\hline
\end{tabular}

TABLE 4: Results base case volume estimation

\begin{tabular}{|l|l|l|l|l|l|}
\hline $\begin{array}{l}\text { Structure } \\
\text { (Bulk volume) }\end{array}$ & porosity & Sw & NTG & Boi & STOIIP (STB) \\
\hline 10,964 & 0.266 & 0.43 & 0.75 & 2.2 & $5,892,752.65$ \\
\hline
\end{tabular}

TABLE 5: Results of final volume probabilistic estimation

\begin{tabular}{|l|l|}
\hline Cases & STOIIP $(\mathbf{S T B})$ \\
\hline Low & $5,198,470.887$ \\
\hline Base & $5,892,752.651$ \\
\hline High & $6,451,196.678$ \\
\hline
\end{tabular}

\section{Results of deterministic approach}

Results of deterministic analysis using six uncertainty parameters which are structure, water saturation, contact, porosity, net to gross (NTG) ratio and initial oil formation volume factor $\left(\mathrm{B}_{\mathrm{oi}}\right)$ showed that the base case was constant with STOIIP value of approximately
5.8MMSTB for all six parameters. However, low case results indicated a minimum value of 5.20MMSTB for structures and maximum value of 6.2MMSTB for water saturation. High case results revealed a maximum of 6.45MMSTB for structures and a minimum value of 5.69MMSTB for water saturation (Table 6 and Fig. 7).

TABLE 6: Results of deterministic sensitivity analysis

\begin{tabular}{|l|l|l|l|}
\hline \multirow{2}{*}{ Uncertainty parameter } & STOIIP (MMSTB) & STOIIP (MMSTB) & STOIIP (MMSTB) \\
\cline { 2 - 4 } & Low case & Base case & High case \\
\hline STRUCTURE & 5.20 & 5.8 & 6.45 \\
\hline SATURATION & 6.20 & 5.8 & 5.69 \\
\hline CONTACT & 5.88 & 5.8 & 5.90 \\
\hline POROSITY & 5.76 & 5.8 & 6.03 \\
\hline NTG & 5.81 & 5.8 & 5.97 \\
\hline Boi & 5.89 & 5.8 & 5.84 \\
\hline
\end{tabular}




\section{Tornado Chart}

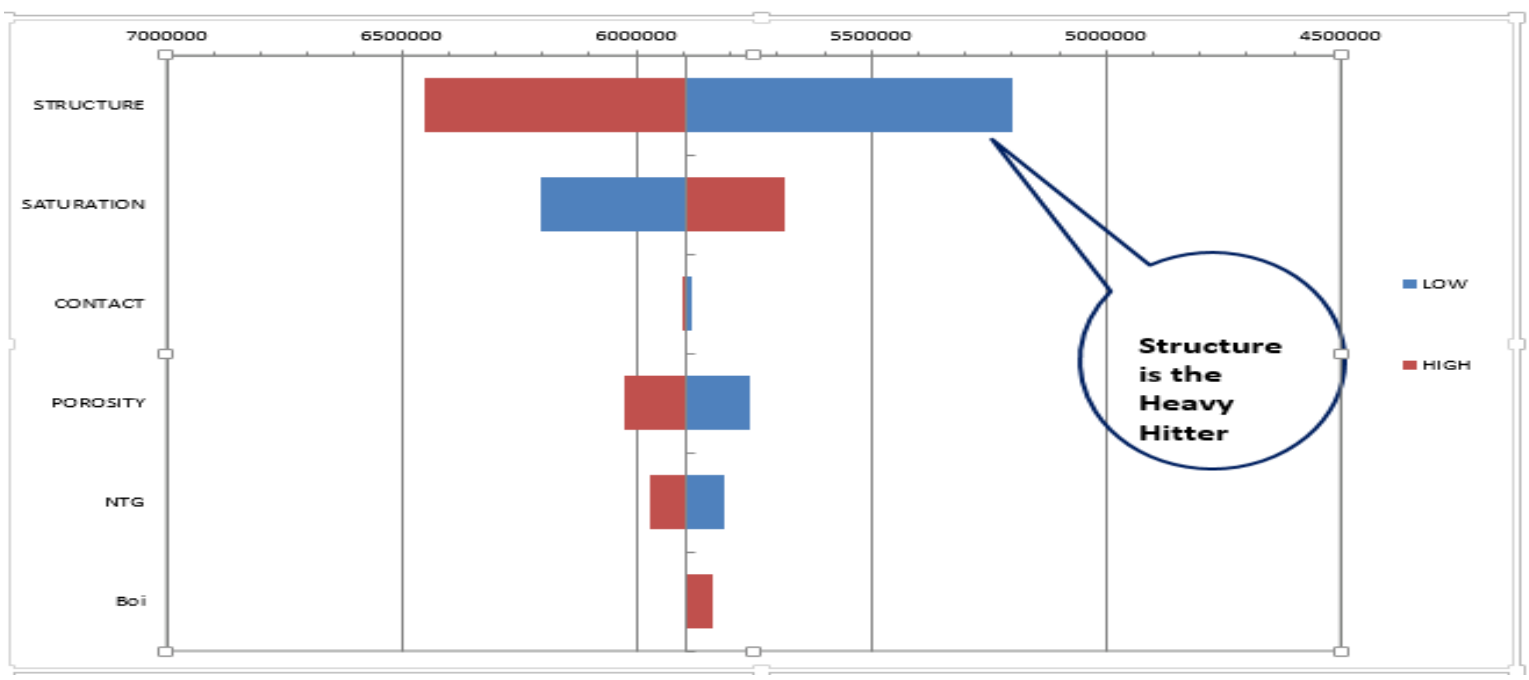

Fig. 7: Result of tornado diagram of reservoir parameters.

\section{DISCUSSION}

The residual sand correlation uncertainty result of the five wells Dan-002, Dan-001, Dan-005, Dan-003 and Dan-004 gave residuals in the range -65.3 to 60 which was obtained by subtracting values of horizon after from the Z-values components of the wells as seen in Table 1. Average estimates and standard deviation was calculated as seen in Table 2.

Results of low and high case strings for reservoir I was done by the Petrel software with different sensitivity properties such as structure, contact, water saturation $\left(S_{w}\right)$, Net to gross ratio (NTG), porosity $(\varphi)$, and initial oil formation volume factor $\left(\mathrm{B}_{\mathrm{oi}}\right)$ as seen in Table 3.

Results of this modeling indicated the geosensitivity of structures in this reservoir and the reservoir estimation (STOIIP) for the base case at 5,892,752.65STB as seen in Table 4. The STOIIP estimates for the low and high cases are $5,198,470.887$ STB and $6,451,196.678$ STB as seen in Table 5. Now when the uncertainty parameters were inputed for the three cases of low, base and high results shows that structure was severly affected in the high case scenario and was quantified as 6.45MMSTB produced an acceptable value in the low case with approximately 5.20MMSTB while the base case which is the control gave a volume of 5.8MMSTB for all the uncertainty parameters (Table 6 ).

\section{CONCLUSIONS}

The main uncertainties for the I-sand complex have been identified and evaluated via a thorough statistical uncertainty analysis. The uncertainty identification and quantification exercise will help to improve the reserve estimates and ultimately support field development. The key uncertainties impacting the statics OIIP includes structures and water saturation.

These were used to evaluate some of the uncertainties in the volumetric parameters for use in probabilistic volumetric. The statistical or probabilistic method used is a pragmatic approach to quantify the uncertainty ranges in reservoir parameters. They showed appreciable impact on the on statics volumes as well as improved chances of recovery. This justified its choice as the best approach although it depends on the deterministic approach.

\section{NOMENCLATURE}

$B_{o i}-$ Initial oil formation volume factor

GOC - Gas oil contact

GRV - Gross rock volume

HAFWL - Height above free water level

$\mathrm{HC}$ - High case

LC - Low case

MMSTB $=$ million standard barrel

NTG - Net to gross ratio

OOIP - Original oil in place

OWC - Oil water contact

PVT - Pressure volume temperature

STOIIP - Stock tank oil initial in place

\section{REFERENCES}

Ayoola, E. O., 2004. Volumetric of field in Eastern Niger Delta, Nigeria. Proceedings of the 23rd Annual Nape International Conference, (NAPE'04), Lagos Nigeria: 10-16.

Bickel, J. E. and Bratvold, R. B., 2008. From Uncertainty Quantification to Decision Making in the Oil and Gas Industry. Energy Exploration \& Exploitation Journal, 26: 311-325.

Castillo, J., Sanchez, M. and Rodriguez, M., 1998. Integrated reservoir characterization and 
volumetric analysis of the analysis of the Arecuna field (3D seismic area).

D., 2005. Project risk management Guidelines: Managing Risk in Large Projects and Complex Procurements. John Wiley and Sons, Ltd, England, 15.

Department of Petroleum Resources (DPR) (1996). Guidelines for the Farm-out and Operations of Marginal Fields.

Efeotor, J., 1999. Fundamentals of Petroleum Geology. Paragraphic Press, Port-Harcourt, Nigeria: 5159.

Egbogah, E. O., 2008. Onshore/Marginal Field Developments: Challenges, Opportunities and Prospects for the Future. Presented at 2011 SPE Annual Oloiribi Lecture and Energy Forum, Lagos, Nigeria, June30.

Floris, F. J. and Peersmann, M., 2002. Integrated scenario and probabilistic analysis for asset decision support. Petroleum geosciences, 8, 16.

Gilman, J. R. Brickey, R. T. and Redd, M. M., 1998. Monte Carlo Techniques for Evaluating Producing Properties. Paper SPE 39925 presented at the 1998 SPE Rocky Mountain Regional Low Permeability Reservoirs
Symposium, Denver, 5 - 8April.

Graf, T., 2005. Shifting the Gaussian Curve to the Right - A Fully Stochastic Approach to Marginal Offshore Field Development. Paper SPE 94206 presented at the SPE Europe/EAGE Annual Conference held in Madrid, Spain, 13-16 June.

Haldorsen, H. and Damsleth, E., 1993. Challenges in reservoir characterization. Geohorizon journal, 77(4): $541-551$.

Ilozobhie, A. J. and Egu, D. I., 2013. Predicting the Behaviors of Multilayered Reservoirs to Cummulative Production in a Commingled Zone. International Journal of Natural and Applied Science, Vol. 8 (1 \& 2), pp 92-107.

Ilozobhie, A. J., Obi, D. A., Okwueze, E. E. and Okereke, C. S., 2014. Geophysical Studies of Parts of Bornu Basin from Seismic, Well Log and Aeromagnetic Data. World Journal of Applied Science and Technology, Vol. 6(2), PP 105-113.

Ilozobhie, A. J., Obi, D. A. and Okwueze, E. E., 2015. Geostatistical Analysis of Porosity Distribution from Well Log Data in Parts of Bornu Basin North-Eastern Part, Nigeria Using Kriging and Co-kriging Methods. Advances in Applied Science Research, Vol. 6(2), pp 83-95. 